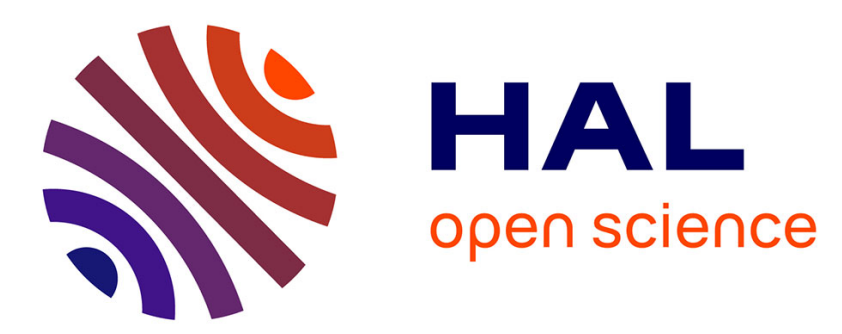

\title{
Convergent Access to Bis-spiroacetals through a Sila-Stetter-Ketalization Cascade
}

Jessica Labarre-Lainé, Redouane Beniazza, Valérie Desvergnes, Yannick Landais

\section{- To cite this version:}

Jessica Labarre-Lainé, Redouane Beniazza, Valérie Desvergnes, Yannick Landais. Convergent Access to Bis-spiroacetals through a Sila-Stetter-Ketalization Cascade. Organic Letters, 2013, 15 (18), pp.4706-4709. 10.1021/ol402017x . hal-03128830

\section{HAL Id: hal-03128830 https://hal.science/hal-03128830}

Submitted on 2 Feb 2021

HAL is a multi-disciplinary open access archive for the deposit and dissemination of scientific research documents, whether they are published or not. The documents may come from teaching and research institutions in France or abroad, or from public or private research centers.
L'archive ouverte pluridisciplinaire HAL, est destinée au dépôt et à la diffusion de documents scientifiques de niveau recherche, publiés ou non, émanant des établissements d'enseignement et de recherche français ou étrangers, des laboratoires publics ou privés. 


\title{
A Convergent Access to Bis-spiroacetals Through a Sila-Stetter-ketalization Cascade
}

\author{
Jessica Labarre-Lainé, ${ }^{\S}$ Redouane Beniazza, ${ }^{\S}$ Valérie Desvergnes \\ and Yannick Landais*
}

Université de Bordeaux, Institut des Sciences Moléculaires, UMR-CNRS 5255

351, cours de la libération, 33405 Talence, Cedex (France)

y.landais@ism.u-bordeauxl.fr

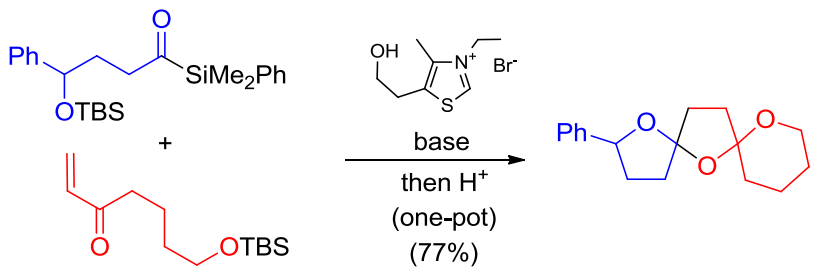

An NHC-catalyzed sila-Stetter reaction between aliphatic acylsilanes and vinylketones bearing silyl ether substituents affords functionalized 1,4-diketones, which upon treatment under acidic conditions leads to the corresponding bis-spiroacetals. The two-step sequence may be also carried out in a one-pot operation leading to high yields of the desired bis-spiroacetals.

The bis-spiroacetal skeleton is found in various bioactive marine phycotoxins including pinnatoxin A 1, spirolide C 2 (Figure 1) or pteriatoxins (not shown). ${ }^{1}$ These toxins have led recently to intensive research due to their potent acute neurotoxicity. ${ }^{2}$ The nature of the tricyclic system, embedded in a complex macrocycle, varies with the size of the oxygenated rings (5 and 6membered rings) forming the bis-spiroacetal. Several strategies directed toward the elaboration of these bisspiroacetals have been devised en route to the total synthesis of $\mathbf{1}$ and $\mathbf{2} \cdot{ }^{3,4}$ A straightforward disconnection leading to this skeleton implies the generation of a 1,4diketone, which upon ketalization under acidic conditions provides the desired tricyclic framework. ${ }^{4}$

\footnotetext{
${ }^{\S}$ These authors contributed equally to the work.

(1) For a review on the isolation, structure and biogenesis of these marine toxins, see: Kita, M.; Uemura, D. Chem. Lett. 2005, 34, 454-459.

(2) (a) Munday, R.; Quilliam, M. A.; LeBlanc, P.; Lewis, N.; Gallant, P.; Sperker, S. A.; Stephen E. H.; MacKinnon, S. L. Toxins 2012, 4, 114. (b) Araoz, R.; Servent, D.; Molgo, J.; Iorga, B. I.; Fruchart-Gaillard, C.; Benoit, E.; Gu, Z.; Stivala, C.; Zakarian, A. J. Am. Chem. Soc. 2011, 133, 10499-10511.

(3) (a) McGarvey, G. J.; Stepanian, M. W. Tetrahedron Lett. 1996, 37, 5461-5464. (b) Meilert, K.; Brimble, M. A. Org. Biomol. Chem. 2006, 4, 2184-2192. (c) Georgiou, T.; Tofi, M.; Montagnon, T.; Vassilikogiannakis, G. A. Org. Lett. 2006, 8, 1945-1948. (d) Furkert, D. P.; Brimble, M. A. Org. Lett. 2002, 4, 3655-3658. (e) Volchkov, I.; Sharma, K.; Cho, E. J.; Lee, D. Chem. Asian J. 2011, 6, 1961-1966.

(4) (a) Brimble, M. A.; Furkert, D. P. Curr. Org. Chem. 2003, 7, 1461-1484. (b) Montagnon, T.; Tofi, M.; Vassilikogiannakis, G. Acc. Chem. Res. 2008, 41, 1001-1011.
}

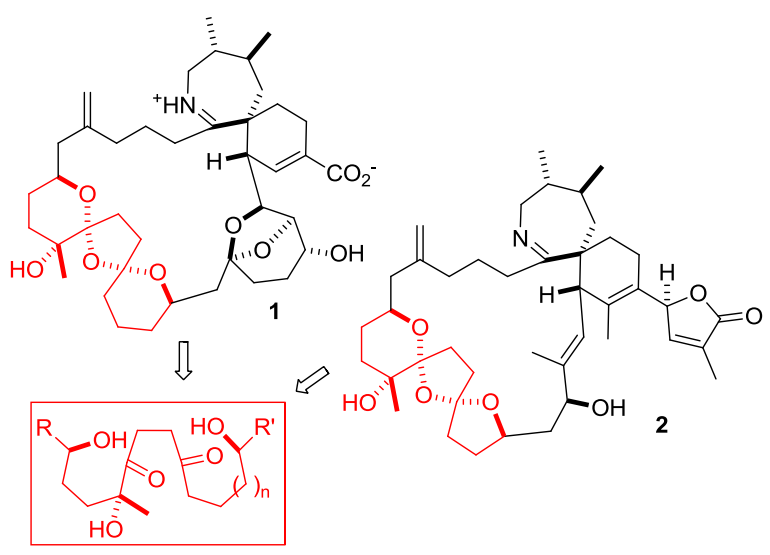

Figure 1. Bis-spiroacetal skeleton in marine phycotoxins

This spiroacetalization has been elegantly pioneered by Kishi $^{5}$ then by Inoue-Hirama, ${ }^{6}$ Nakamura-Hashimoto ${ }^{7}$ and Zakarian ${ }^{8}$ in their respective total syntheses of pinnatoxin

(5) Mc Cauley, J. A.; Nagasawa, K.; Lander, P. A.; Mischke, S. G.; Semones, M. A.; Kishi, Y. J. Am. Chem. Soc. 1998, 120, 7647-7648.

(6) Sakamoto, S.; Sakazaki, H.; Hagiwara, K.; Kamada, K.; Ishii, K.; Noda, T.; Inoue, M.; Hirama, M. Angew. Chem., Int. Ed. 2004, 43, 6505-6510.

(7) Nakamura, S.; Inagaki, J.; Sugimoto, T.; Kudo, M. ; Nakajima, M.; Hashimoto, S. Org. Lett. 2001, 3, 4075-4078.

(8) (a) Lu, C.-D.; Zakarian, A. Org. Lett. 2007, 9, 3161-3163. (b) Stivala, C.; Zakarian, A. J. Am. Chem. Soc. 2008, 130, 3774-3776. 
1, as well as by Ishihara $e t a l$. in their preparation of the bis-spiroacetal core of spirolide B. ${ }^{9}$ The 1,4-diketone motif may be constructed by a number of ways, often requiring several steps. ${ }^{10}$ In the search for a convergent strategy, allowing the presence of functionality and protecting groups on the carbon backbone, the Stetter reaction appeared as an attractive method to elaborate efficiently the bis-spiroacetal $\mathbf{I}$ present in toxins $\mathbf{1}$ and $\mathbf{2}$ (Scheme 1). It was thus envisioned that the coupling of an aldehyde (or an acylsilane) III and a vinyl ketone such as IV in the presence of a suitable organocatalyst (usually a $\mathrm{N}$-heterocyclic carbene (NHC)) would deliver the 1,4diketone framework II. A careful choice of the protecting groups on the alcohol functions within the chain would then allow the construction of the desired bis-spiroacetal I after acid-catalyzed deprotection and ketalization. We report here that NHC-mediated Stetter and sila-Stetter processes followed by the acid-catalyzed ketalization effectively offer a straightforward access to the bisspiroacetal skeleton. A cascade process also allows both events to be carried out in a one-pot operation.

Scheme 1. Retrosynthetic analysis

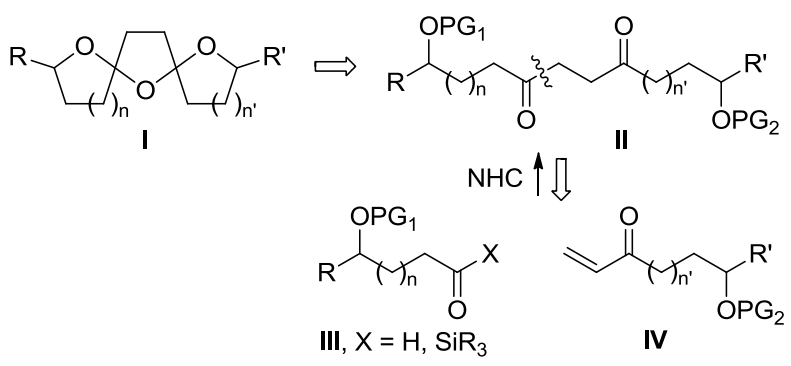

Although the pioneering work by Stetter ${ }^{11}$ and others has shown that this coupling may be carried out starting from a large variety of aldehydes, few examples have been reported to date on aliphatic partners. Moreover, acyloins resulting from the homo-coupling of the aldehyde are often present as by-products. Recent work by Scheidt et $\mathrm{al}^{12}$ however showed that this could be circumvented, using acylsilanes instead of aldehydes, although mostly aromatic acylsilanes were tested during this work. We thus studied first the influence of the nature of the partner III in the Stetter reaction, using as precursors, aldehyde $\mathbf{3}$ or acylsilane $\mathbf{4 a}$ and vinylketone $\mathbf{5 a}$ in the presence of NHC-catalyst precursor $\mathbf{A} \cdot{ }^{13}$ As summarized in Table 1, using aldehyde $\mathbf{3}$ and various amounts of catalyst invariably led to a mixture of both the

(9) Ishihara, J.; Ishizaka, T.; Suzuki, T.; Hatakeyama, S. Tetrahedron Lett. 2004, 45, 7855-7858.

(10) Enders, D.; Niemeier, O.; Henseler, A. Chem. Rev. 2007, 107, 5606-5655.

(11) (a) Stetter, H. Angew. Chem. Int. Ed. Engl. 1976, 15, 639-647. (b) Moore, J. L.; Rovis, T. Top. Curr. Chem. 2009, 291, 77-144.

(12) (a) Scheidt, K. A.; Bharadwaj, A. R.; Mattson, A. E. J. Am. Chem. Soc. 2004, 126, 2314-2315. (b) Mattson, A. E.; Bharadwaj, A. R.; Zuhl, A; M.; Scheidt, K. A. J. Org. Chem. 2006, 71, 5715-5724.

(13) A screening of other thiazolium salts led to similar results (supporting information). Catalyst $\mathbf{A}$ was finally selected, being the easiest to handle. desired product 6a and the corresponding acyloin 7 (Entries 1-3, Table 1). In contrast, we were pleased to observe that acylsilane 4a led to 6a in good yield, without a trace of 7 (entries 4-5), thus notably extending the scope of the sila-Stetter reaction. ${ }^{12}$ Increasing the quantity of acylsilane however produced small amount of $\mathbf{7}$ (entry 6).

Table 1. Stetter versus sila-Stetter reaction

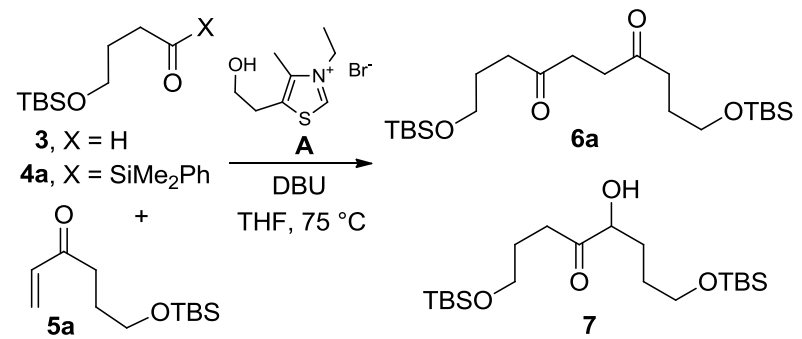

\begin{tabular}{cccccc}
\hline entry & $\mathbf{3}$ or $\mathbf{4 a}$ (equiv) & $\mathbf{A}(\mathrm{mol} \%)$ & $t(\mathrm{~h})$ & $\mathbf{6 a} / 7^{a}$ & $\begin{array}{c}\text { yield }^{b} \\
(\%)\end{array}$ \\
\hline 1 & $\mathbf{3}(1)$ & 30 & 2 & $81 / 19$ & 61 \\
2 & $\mathbf{3}(1.5)$ & 15 & 2.5 & $72 / 28$ & 68 \\
3 & $\mathbf{3}(2)$ & 30 & 2 & $65 / 35$ & 77 \\
4 & $\mathbf{4 a}(1)^{\mathrm{c}}$ & 30 & 1.5 & $100 / 0$ & 67 \\
5 & $\mathbf{4 a}(1.5)^{\mathrm{c}}$ & 15 & 3 & $100 / 0$ & 89 \\
6 & $\mathbf{4 a}(2)^{\mathrm{c}}$ & 30 & 3 & $80 / 20$ & 90
\end{tabular}

${ }^{a}$ Measured by ${ }^{1} \mathrm{H}$ NMR of the crude reaction mixture. ${ }^{b}$ Isolated yield of $6 \mathbf{a}$ after column chromatography. ${ }^{\mathrm{c}} 4$ equiv of $i$-PrOH were used.

Optimization of the sila-Stetter reaction showed that decreasing the quantity of acylsilane was detrimental to the conversion, with 1.5 to 2 equivalents leading to optimal results. Dry iso-propanol (4 equiv) and DBU as a base were also shown to provide the highest yields. With these optimized conditions in hand, the methodology was extended to a large variety of aliphatic acylsilanes ${ }^{14}$ and enones $^{15}$ precursors (supporting information), as illustrated in Scheme 2.

(14) Clark, C. T.; Milgram, B. C.; Scheidt, K. A. Org. Lett. 2004, 6 , 3977-3980. 3818 . 
Scheme 2. sila-Stetter reaction between aliphatic acylsilanes 4 and vinylketones $\mathbf{5}$

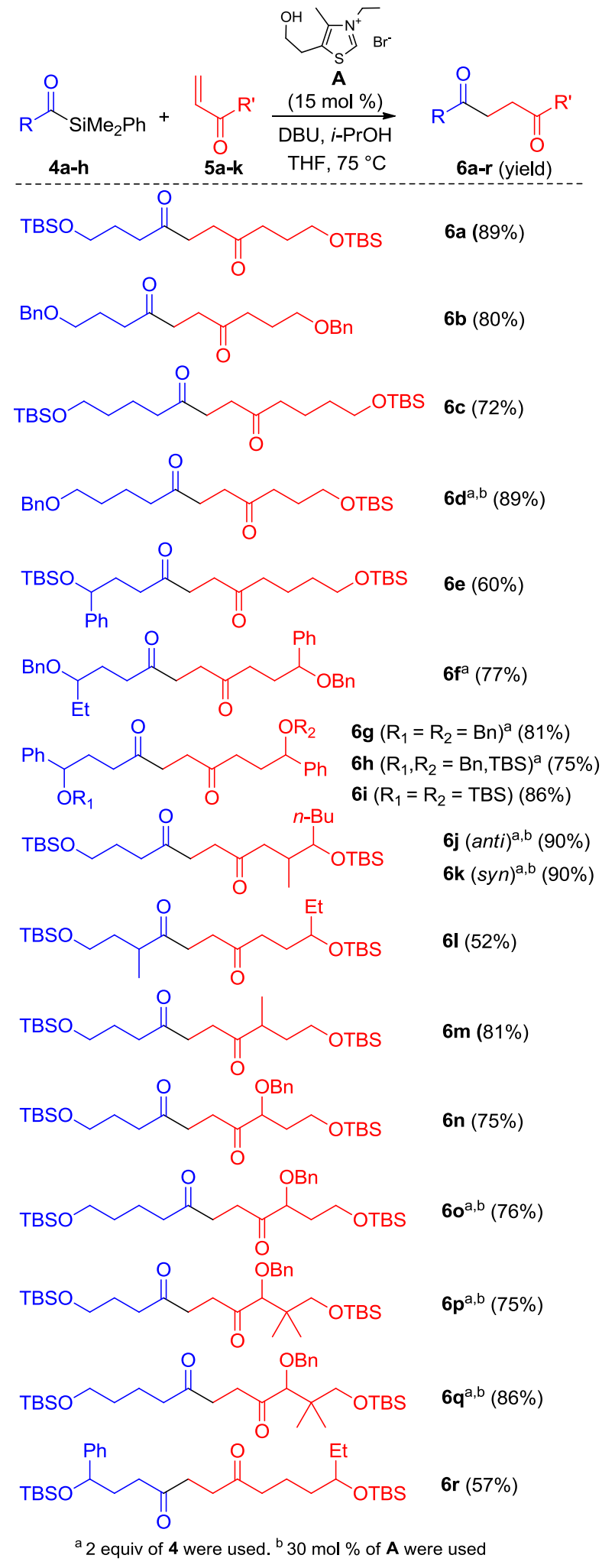

$t$-Butyldimethylsilyl and benzyl substituents were selected as orthogonal protecting groups for alcohol functions, so that they can be deprotected selectively if needed (vide infra). 1,4-Diketones were obtained in good to excellent yields. ${ }^{16}$ Reaction time ranged between 3 and 24 hours depending on the nature of the substrate. 1.5 equivalent of acylsilane was generally used except when indicated. As mentioned above, the reaction was carried out using $15 \mathrm{~mol} \%$ of salt $\mathbf{A}$, except for the preparation of $\mathbf{6 d}, \mathbf{6 j}-\mathbf{k}$ and $\mathbf{6 o - q}$, where $30 \mathrm{~mol} \%$ were employed. It is noteworthy that substitution on the carbon chain is allowed on both partners, but $\alpha$-substitution in acylsilane was shown to slow down the process, leading to lower yields. ${ }^{17}$ Removal of the $t$-butyldimethylsilyl protecting group was then carried out under standard acidic conditions, leading to a spontaneous cyclization, ${ }^{5-8}$ producing the desired bis-spiroacetals in moderate to good yields as a mixture of diastereomers (d.r. estimated using both ${ }^{1} \mathrm{H}$ NMR and GC-MS) (Scheme 3). ${ }^{18}$ Various acidic conditions were tested ( $\mathrm{TfOH}, \mathrm{HCl}, \mathrm{MgBr}$, $\mathrm{BF}_{3}$. OEt2, TMSOTf, $\left.\mathrm{Sc}(\mathrm{OTf})_{3}\right)$ but camphorsulfonic acid (CSA) in $\mathrm{CH}_{3} \mathrm{CN}$ at room temperature was found optimal in terms of yields. In some cases, major diastereomers were obtained pure after chromatography, but their structures could not be attributed based solely on 1D and 2D NMR data. Attempts at obtaining crystals for X-ray diffraction studies unfortunately failed.

Scheme 3. Spiroacetalization of 1,4-diketones 6e, 6i, 6n-q

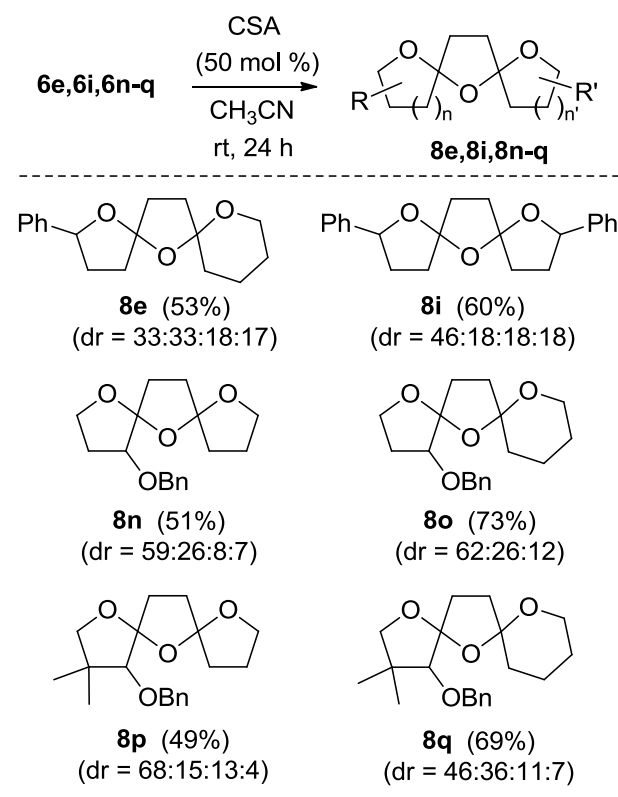

When the deprotection was carried out using CSA in $\mathrm{MeOH}$ as reported by Ishihara et $a l,{ }^{9}$ bis-acetal 9 was obtained as a mixture of diastereomers instead of the corresponding bis-spiroacetal (Scheme 4). Interestingly, the structure of the major isomer could be determined through X-ray diffraction studies.

(16) It was also possible to perform reaction between acylsilanes 4 and other Michael acceptors such as acrylonitrile (51\%), methylacrylate $(36 \%)$ and vinylsulfone $(26 \%)$ (unoptimized yields) (Supporting Information).

(17) Increasing the amount of acylsilane $4 \mathbf{h}$ to 2.5 equiv resulted in the isolation of $\mathbf{6 1}$ but in only $42 \%$ yield.

(18) Thermodynamic ratio under the given conditions. 
Scheme 4. Spiroacetalization of $\mathbf{6} \mathbf{i}$ in $\mathrm{MeOH}$

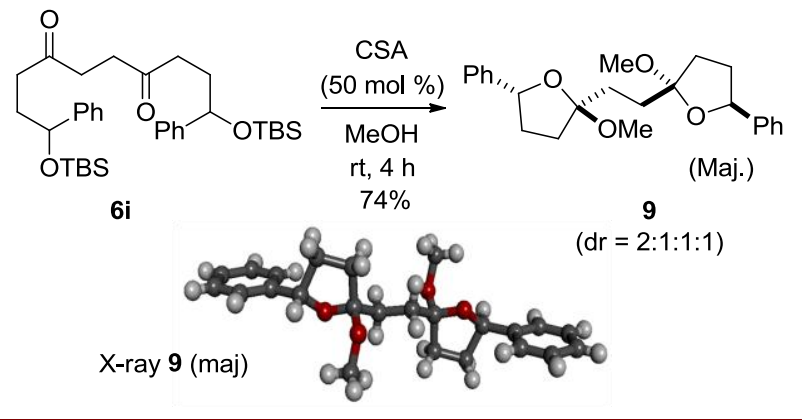

Having demonstrated the efficiency of the sila-Stetter reaction and the acid-mediated spiroacetalization of the resulting 1,4-diketones, we then developed a one-pot process, in order to avoid the purification of the sensitive diketone intermediate. The sila-Stetter reaction was performed using as above precatalyst $\mathbf{A}$, DBU and $i$ $\mathrm{PrOH}$. After heating the mixture at $75^{\circ} \mathrm{C}$ until complete disappearance of enone 5, CSA (50 mol\%) was added and the reaction mixture stirred at room temperature. This afforded the required bis-spiroacetals 8a,c,e,i in good yields (Scheme 5). It is worthy of note that $\mathbf{8 e}$ and $\mathbf{8 i}$ were obtained with slightly better yields than those observed using the two-pot protocol (77\% vs $53 \%$ and $68 \%$ vs $60 \%$ respectively). The major diastereomer for $8 \mathbf{a}$ and $\mathbf{8 c}$ was obtained pure in each case, and the relative configuration was attributed based on literature reports. ${ }^{3 e, 19}$

Scheme 5. One-pot sila-Stetter/spiroacetalization cascade

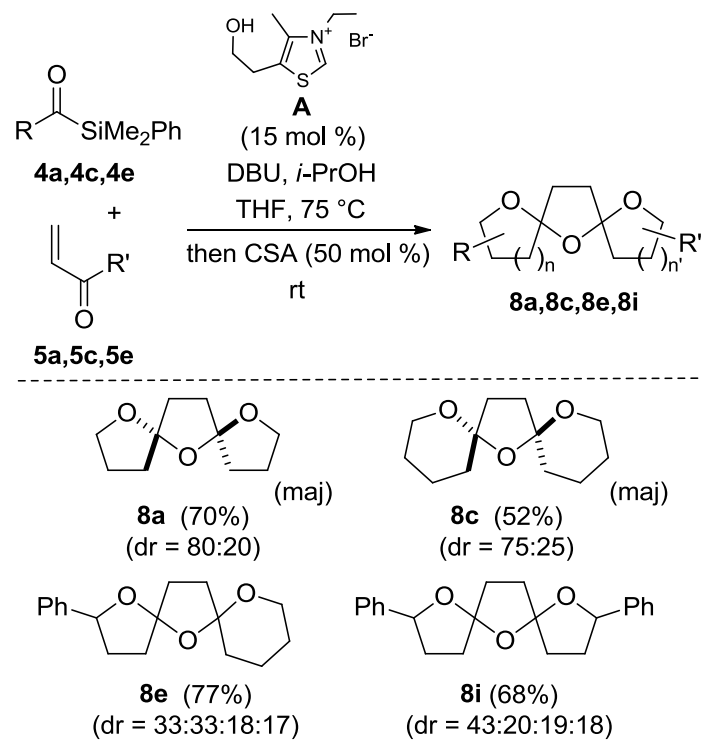

Finally, orthogonal protecting groups on 1,4-diketones allow for the mono-deprotection and the selective formation of tetrahydrofurans. For instance, treatment of 1,4-diketone 6d under Lewis acidic conditions, triggered the selective deprotection of the TBS group, followed by the cyclisation and the formation of an oxonium intermediate, which was eventually trapped in situ by a nucleophilic allylsilane, leading to THF $\mathbf{1 0}$ in good yield (Scheme 6).

Scheme 6. One-pot mono-deprotection/cyclisation/allylation of 1,4-diketone $6 \mathbf{d}$

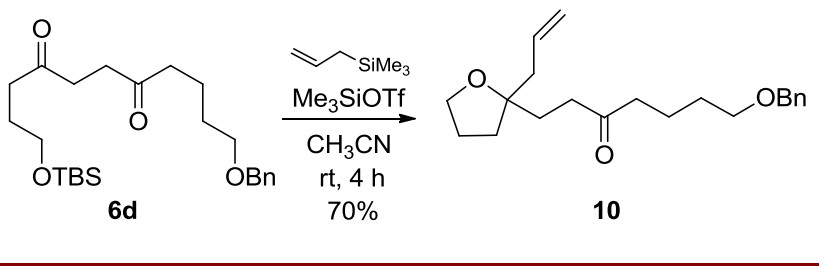

In summary, we reported here the sila-Stetter coupling between a series of aliphatic acylsilanes and vinylketones, which afforded in generally good yields, 1,4-diketones bearing ether substituents on the chain. Subsequent acidmediated deprotection of silyl ether protecting groups triggered an efficient spiroacetalization, leading to bisspiroacetal motifs, which are present in marine natural products such as pinnatoxin 1. Both successive transformations may be carried out in a one-pot operation with high efficiency. Application of this strategy to the synthesis of bis-spiroacetal fragments of spirolides and analogues is now underway and will be reported in due course.

Acknowledgment. We thank Dr. V. Liautard, Dr. S. Toumieux and D. Morgant (ISM, Bordeaux) for preliminary experiments, CNRS, MNERT, ANR (Spirosyn $\mathrm{N}^{\circ}$ 11-BS07-006-02) for generous support, Dr. C. Guillou, L. Chabaud (ICSN, Gif s/Yvette) and Dr. F. Robert (ISM, Bordeaux) for fruitful discussions. We are grateful to Dr. B. Kauffmann (IECB, Bordeaux) for X-ray diffractions studies, J.M. Lasnier and N. Pinaud (ISM, Bordeaux) for NMR experiments.

Supporting Information Available: Experimental procedures and spectroscopic data for compounds 4-10 and morpholine and Weinreb amide precursors are available in the electronic supporting information. Copies of ${ }^{1} \mathrm{H}$ and ${ }^{13} \mathrm{C}$ NMR spectra for all new compounds are also supplied. This material is available free of charge via the Internet at http://pubs.acs.org. 